\title{
Study of Movement of Coarse Aggregates in the Formation Process of Asphalt Mixture in the Laboratory
}

\section{Hui Guo', Yongli Zhao' ${ }^{2}$, Deyu Zhang ${ }^{3}$, Min Shang ${ }^{4}$}

1. School of Transportation, Southeast University, Nanjing, Jiangsu 210096, China

2. School of Transportation, Southeast University, Nanjing, Jiangsu 210096, China

3. School of Civil Engineering and Architecture, Nanjing Institute of Technology, Nanjing, Jiangsu 211167, China

4. School of Transportation, Southeast University, Nanjing, Jiangsu 210096, China

\begin{abstract}
In this paper, attempts have been made to build an equivalent-sphere mathematical model with respect to length, width, and thickness, in order to describe the coarse aggregates of asphalt mixture in the laboratory. The values of diameters calculated separately based on lengths, widths, and thicknesses have been compared to the model with actual values, which were obtained by two-dimensional digital image processing technique. Certain characteristics of movements were observed during the formation process. The results indicate that an increase of compaction time is accompanied by an increase in average diameter of $2 \mathrm{D}$ coarse aggregates and its standard deviation. This shows that the rotations of the coarse aggregates and their better packing effect increase with compaction time. The results also imply that there may be a considerable breaking of coarse aggregates between compaction of 40 to 60 times.
\end{abstract}

Keywords: Coarse aggregates distribution; Rotating; Crush; Image analysis

\section{Introduction}

A typical asphalt pavement is made up of $86 \%$ of aggregates, $10 \%$ of asphalt cement, and $4 \%$ air-voids by volume. Generally, the morphological characters of coarse aggregates are described by the following aspects: shape, size, angularity, and surface texture. Digital image processing 
technique has been applied for the study of micro-structures of bituminous mixture, since the 1990s [1]. A substantially large number of researches now focus on digital image processing for two aspects, one is a two-dimensional method (2-D), the other one is a three dimensional method (3-D) [2-4]. The former approach is more cost-effective. However, the captured features and quantified parameters used to evaluate the angularity and surface texture of coarse aggregates, through 2-D imaging techniques, are in most of the published researches, just employed to study the relatively simple aggregate structure. A few of them are applied for studying complex structures. 3-D imaging technique employs X-ray computed tomography, which is a technology using computer-processed X-ray data to reproduce images of fault areas of the scanned object, which allow the user to detect the common internal structures in a non-destructive manner. Fig. 1 is a typical CT scanning system. However, the cost of the CT is high and the $3 \mathrm{D}$ algorithm is complex, and even if the construction of a three-dimensional specimen is completed, the next mechanical test next would not be so satisfactory.

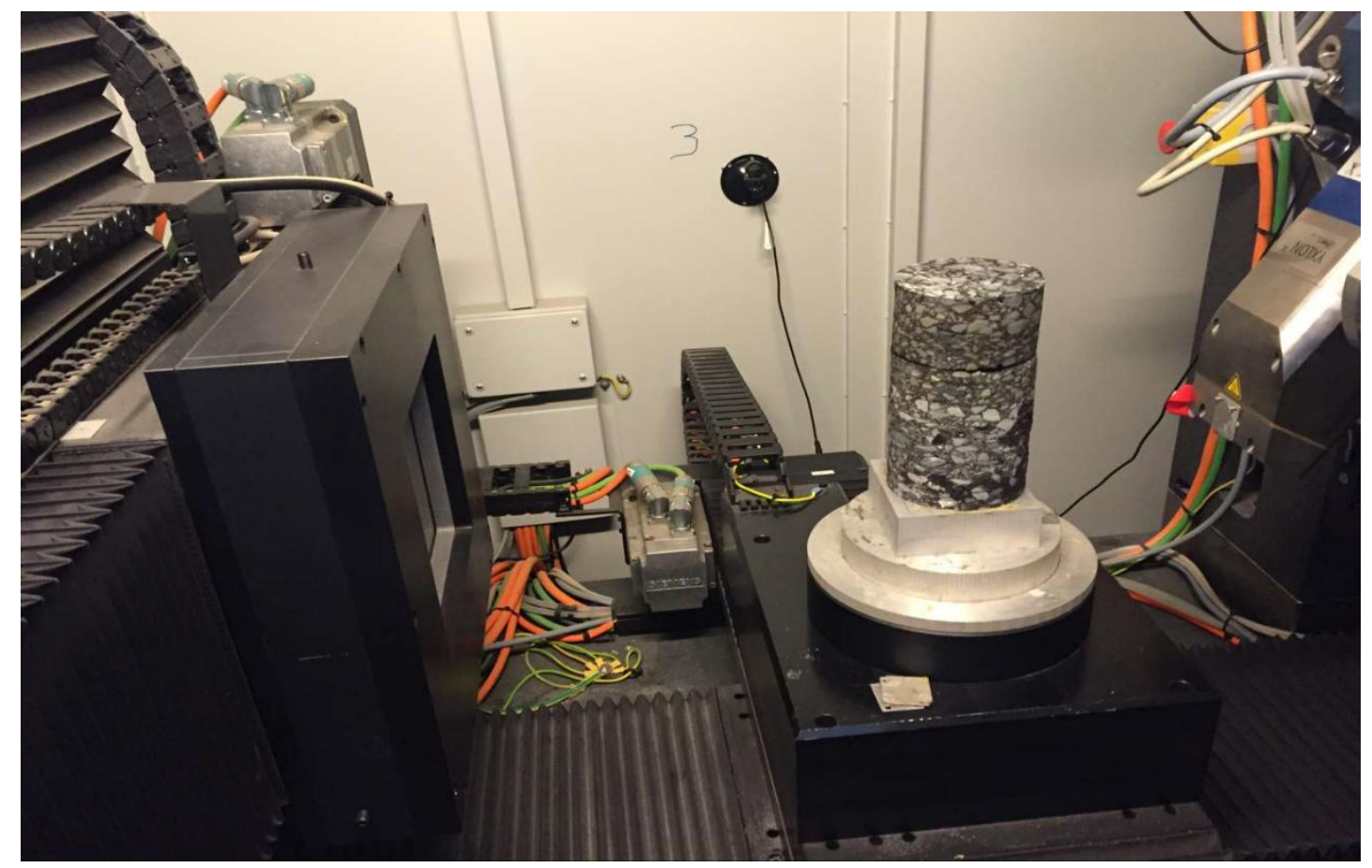

Fig. 1. X-ray CT process during the 3-D imaging technique

Another kind of recent computer simulation technology, which is based on discrete elements, such as PFC3D, provides a useful method to obtain virtual coarse aggregates. However, it is too idealistic to describe the real form of the coarse aggregates completely through a mathematical model. For a long time, researchers have been trying to clarify the changes in coarse aggregates, during the shaping process, which include location, movement, and rotation. Despite its advantage over other technologies in the research, the discrete element method is based on ideal assumptions to a great extent, to be real and feasible [12].

Compared to this method, image processing has the advantage of being reliable and to the point. To study the mechanism of formation of the asphalt mixture indoors, the image processing technique is applied to have an in-depth understanding of the movement of the coarse aggregates in the mixture forming process. 


\section{Mathematical model}

The main focus was on the cutting process, in order to obtain the statistical distribution of the two-dimensional equivalent diameter of coarse aggregates, assuming that the mixture was completely homogenized. Even valuable information about changes in coarse aggregates, which could not be homogenized, due to different aggregate shapes, constraints in forming space, forming methods, and so on, could still be obtained. Coarse aggregates in asphalt mixture were composed of different particles and each particle was irregular and hard to describe. Geometric description of coarse aggregate particles is a hotpot also. Researches have shown that the feasible way to establish a model is to describe the asphalt mixture based on particle size [13].Fig. 2 shows the basic model of the sphere method and the rounds cut from it. The spheres in this model represent the sizes of the mineral particles in the mixture.

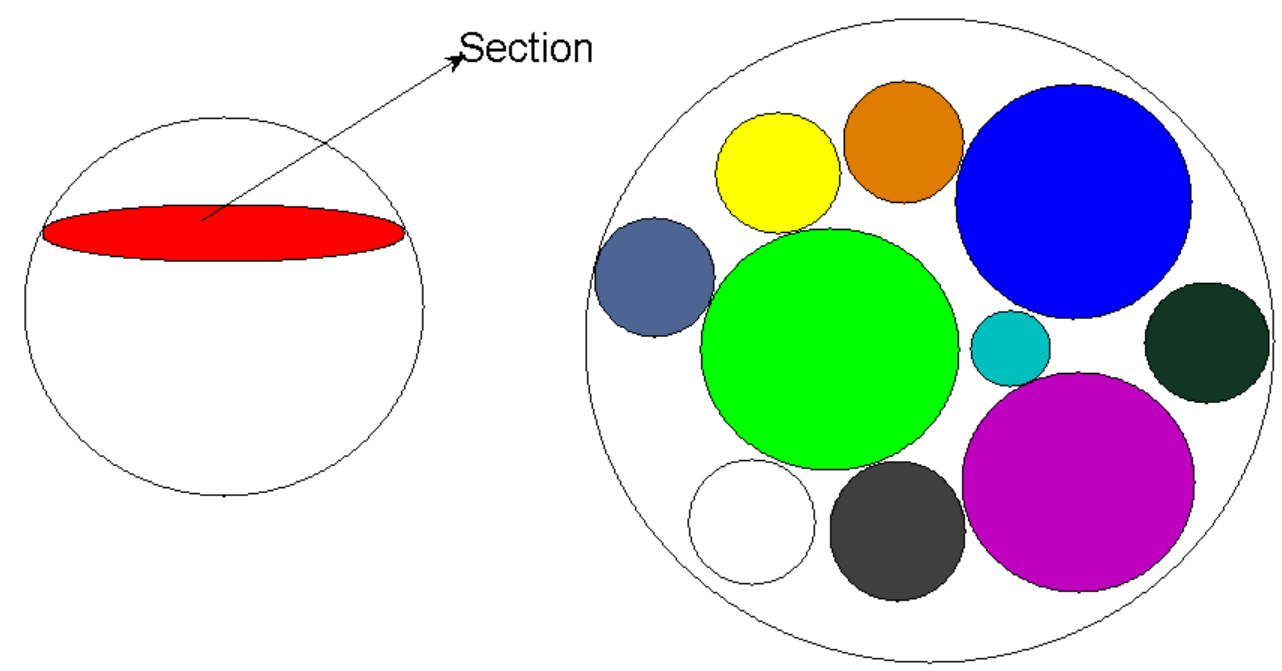

Fig. 2. Particle spheres model and cut rounds

Plane diameter exist mathematical expectation, when a ball of radius $R$ is cut. The radius of the ball is divided into $n$ segments. Thus the radius of the plane is $n$ possible lengths correspondingly, with a probability value of $1 / n$. The definition of mathematical expectation gives equation 1 , which can be simplified to equation 2 .

$$
E(2 R)=2 \lim _{n \rightarrow \infty} \frac{1}{n}\left(\sqrt{R^{2}-\sum_{m=1}^{n}\left(\frac{m}{n} R\right)^{2}}\right.
$$

$$
E(2 R)=2 \sqrt{\frac{2}{3}} R
$$

Assuming that the size of the asphalt mixture is large enough, there will be a distribution for the aspect of particle diameter. The distance from center of the sphere to cut-section is $r$, radius of sphere is $R$, and the radius of the cut-circle is $\mathrm{d}(r)$. 


$$
\mathrm{d}(r)=2 \sqrt{\left(\frac{R}{2}\right)^{2}-r^{2}}
$$

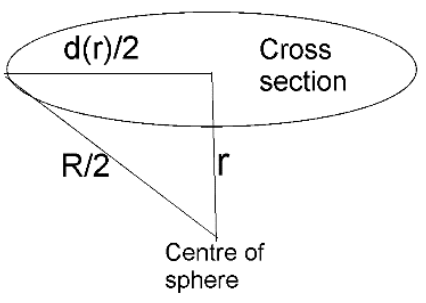

Fig. 3. Cross-sectional size of the circle

Equation 3 is a continuous random distribution function. This paper puts forth a method for discretization of continuous independent variable.

Discretize the function by dividing $r$ into 100 equal

parts and integrating each segment, which will increase the integration domain by 100 times. Fig. 4 is the distribution histogram for the diameter of any cross-section of the circle.

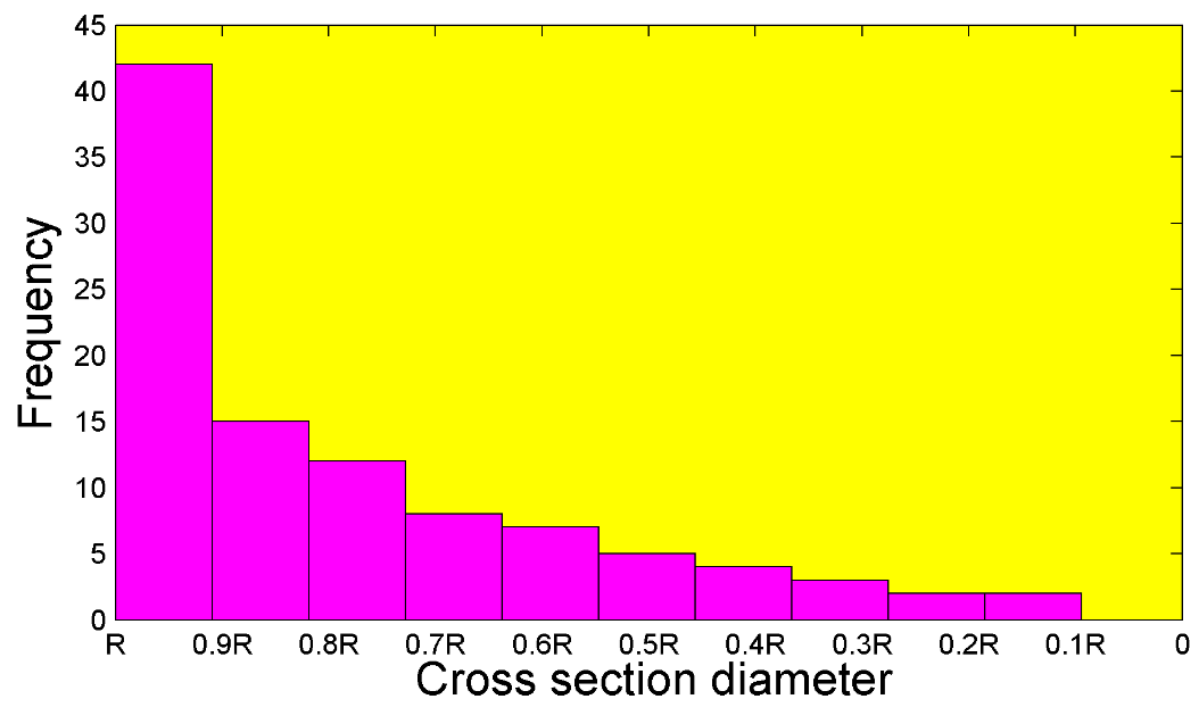

Fig. 4. 2D histogram of particle size distribution

Asphalt mixture is not composed of single size mineral aggregates, but based on different sized particles and different gradation composition. Based on gradation, the coarse aggregates with varying particle sizes are present in proportions. For the continuity gradation asphalt mixture, a nominal particle size of $19 \mathrm{~mm}$ was chosen in this paper. The number of particles on the grade $4.75 \mathrm{~mm}-9.5 \mathrm{~mm}$, cannot be limited without constraining the number of particles of $19 \mathrm{~mm}$ in size. For a given proportion of the number of spheres, it is meaningless to set too many spheres. Here, the number of spheres, larger than the grade of $19 \mathrm{~mm}$, is set to 1 . Based on the gradation 
and particle sizes the equivalent number of the balls can be calculated. Consider the AC20 coarse aggregate gradation (the continuity dense grading concrete with a maximum nominal particle size of $19 \mathrm{~mm}$ ) used in our experiment, as an example. Based on the coarse aggregate gradation and size, the number of spheres, larger than the grade of $19 \mathrm{~mm}$, is set to 1 . Then, the number of equivalent spheres on any grade can be computed, such as in table 1.

Table. 1. The number of equivalent balls based on particle size and composition gradation.

\begin{tabular}{llllll}
\hline $\begin{array}{l}\text { Sieve } \\
\text { size }(\mathrm{mm})\end{array}$ & 4.75 & 9.5 & 13.2 & 16 & 19 \\
\hline $\begin{array}{l}\text { Coarse } \\
\text { aggregate } \\
\text { gradation }(\%)\end{array}$ & 18.7 & 16.8 & 12.9 & 14.3 & 1.9 \\
$\begin{array}{l}\text { The number } \\
\text { of balls }\end{array}$ & 630 & 71 & 20 & 13 & 1 \\
\hline
\end{tabular}

The number of sections also requires a reference to the scale of particle size. Computational complexity should be considered for the choice of sections. Although theoretically, a large number of sections enable the expected value to be approximated more accurately, the computational complexity is unacceptable. Thus, constraints are imposed on the choice of sections. The number of sections on the grade is set to 10 to reduce computational complexity and prevent randomness of a single section. The number of coarse aggregate sections on other grades can be computed based on the size of mesh openings. Table 2 shows the equivalent number of cross sections based on particle sizes.

Table. 2. The number of equivalent cross sections.

\begin{tabular}{llllll}
\hline $\begin{array}{l}\text { Sieve } \\
\text { size }(\mathrm{mm})\end{array}$ & 4.75 & 9.5 & 13.2 & 16 & 19 \\
\hline $\begin{array}{l}\text { The number } \\
\text { of cross- }\end{array}$ & 20 & 28 & 34 & 40 \\
sections
\end{tabular}

Aggregates grouped under the same mesh size do not have a single grain size. Zhang Dong's research shows that the length, width, and thickness of coarse aggregates obey normal distribution [14]. The related data is shown in Table 3.

Table. 3. Statistical data for coarse aggregates.

\begin{tabular}{llllllllllll}
\hline $\begin{array}{l}\text { Sieve } \\
\text { size }\end{array}$ & 4.75 & & 9.5 & & 13.2 & & 16 & & 19 & \\
$\mathrm{~mm})$ & & & & & & & & & & \\
& & & & & & & & & & \\
& Mean( & Standar & Mean( & Standar & Mean( & Standar & Mean( & Standar & Mean( & Standar \\
& $\mathrm{mm})$ & $\mathrm{d}$ & $\mathrm{mm})$ & $\mathrm{d}$ & $\mathrm{mm})$ & $\mathrm{d}$ & $\mathrm{mm})$ & $\mathrm{d}$ & $\mathrm{mm})$ & $\mathrm{d}$ \\
& & deviatio & & deviatio & & deviatio & & deviatio & & deviatio \\
& & & $\mathrm{n}(\mathrm{mm})$ & & $\mathrm{n}(\mathrm{mm})$ & & $\mathrm{n}(\mathrm{mm})$ & & $\mathrm{n}(\mathrm{mm})$ & & $\mathrm{n}(\mathrm{mm})$ \\
\hline
\end{tabular}




\begin{tabular}{lcccccccccc}
\hline $\begin{array}{l}\text { Lengt } \\
\mathrm{h}\end{array}$ & 10.43 & 2.43 & 17.87 & 3.10 & 22.74 & 3.63 & 29.71 & 4.94 & 37 & 5.54 \\
$\begin{array}{l}\text { Widt } \\
\mathrm{h}\end{array}$ & 7.60 & 1.64 & 12.97 & 1.68 & 16.67 & 1.60 & 21.01 & 1.85 & 26.84 & 3.24 \\
$\begin{array}{l}\text { Thick } \\
\text { ness }\end{array}$ & 6.78 & 1.65 & 11.25 & 2.05 & 14.32 & 2.23 & 18.25 & 2.91 & 22.56 & 4.03 \\
\hline
\end{tabular}

The three-dimensional sizes of coarse aggregate particles, which are used as three independent variables, all obey the normal distribution. Based on equation 3, equation 4 is obtained. $F$ is cross-sectional diameter expectation.

$F=\frac{2 \int_{0}^{R / 2} \sqrt{\left(\frac{R}{2}\right)^{2}-r^{2}}}{R / 2} d r$

Discretize this function in accordance with table 2. Generate particle size of the sphere randomly, using matlab2011. Particle sizes obey the normal distribution. The number of balls refers to table 1 , the number of sections refers to table 2 , and the normal distribution parameters refer to table 3 . Fig. 5 shows the histograms of the particle size distribution of the circular section of the ore material, considering that the virtual mixture is completely uniform. Then the above five sets of data could be merged to obtain a new histogram.
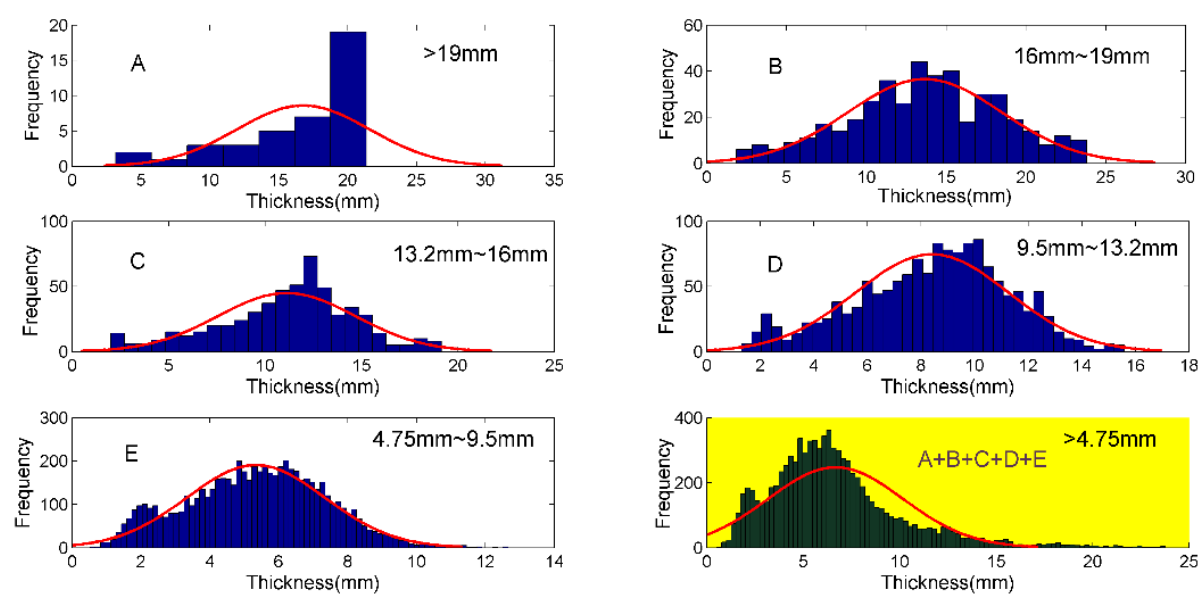

Fig. 5. Histogram showing size distribution of circular particles

In the last figure, the cross-sectional circles having a diameter below $4.75 \mathrm{~mm}$ were removed. The circular cross sections of coarse aggregates are shown in Fig. 6. 

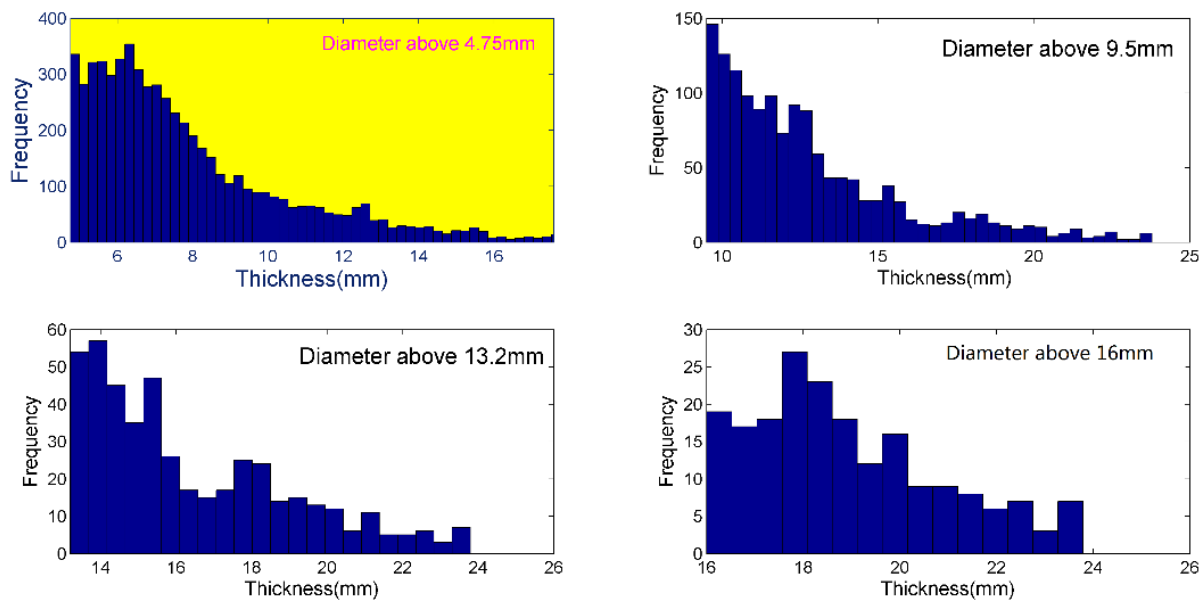

Fig. 6. Histograms showing different circular sizes after sieving

The above data from the mathematical model are presented in Table 4.

Table. 4. The two-dimensional statistical data of coarse aggregates from model.

\begin{tabular}{|c|c|c|c|c|c|c|c|c|c|c|}
\hline \multirow{2}{*}{$\begin{array}{l}\text { Sieve } \\
\text { size( } \\
\mathrm{mm})\end{array}$} & \multicolumn{2}{|l|}{4.75} & \multicolumn{2}{|l|}{9.5} & \multicolumn{2}{|l|}{13.2} & \multicolumn{2}{|l|}{16} & \multicolumn{2}{|l|}{19} \\
\hline & $\begin{array}{l}\text { Mean( } \\
\mathrm{mm})\end{array}$ & $\begin{array}{l}\text { Standard } \\
\text { deviatio } \\
\mathrm{n}(\mathrm{mm})\end{array}$ & $\begin{array}{l}\text { Mean( } \\
\mathrm{mm} \text { ) }\end{array}$ & $\begin{array}{l}\text { Standard } \\
\text { deviatio } \\
\mathrm{n}(\mathrm{mm})\end{array}$ & $\begin{array}{l}\text { Mean( } \\
\mathrm{mm})\end{array}$ & $\begin{array}{l}\text { Standard } \\
\text { deviatio } \\
\mathrm{n}(\mathrm{mm})\end{array}$ & $\begin{array}{l}\text { Mean( } \\
\mathrm{mm} \text { ) }\end{array}$ & $\begin{array}{l}\text { Standard } \\
\text { deviatio } \\
\mathrm{n}(\mathrm{mm})\end{array}$ & $\begin{array}{l}\text { Mean( } \\
\mathrm{mm} \text { ) }\end{array}$ & $\begin{array}{l}\text { Standard } \\
\text { deviatio } \\
\mathrm{n}(\mathrm{mm})\end{array}$ \\
\hline $\begin{array}{l}\text { Lengt } \\
\mathrm{h}\end{array}$ & 15.8 & 7.4 & 18.0 & 6.7 & 20.2 & 6.3 & 22.2 & 6.2 & 25.3 & 6.3 \\
\hline $\begin{array}{l}\text { Widt } \\
\mathrm{h}\end{array}$ & 8.9 & 3.8 & 13.6 & 3.5 & 16.7 & 3.0 & 19.2 & 2.3 & 21.2 & 1.5 \\
\hline $\begin{array}{l}\text { Thick } \\
\text { ness }\end{array}$ & 8.1 & 3.2 & 12.8 & 3.0 & 16.4 & 2.6 & 18.9 & 2.0 & 20.9 & 1.4 \\
\hline
\end{tabular}

\section{Materials and methods}

Gyratory compaction is considered as an effective method for compacting asphalt mixture indoors [15]. According to the AC20 mixture design, the specimens take shape under 30, 40, 50, 60, 80 times gyratory compaction, which represent different compaction efforts. The cross-sectional images are obtained by cutting each specimen into five slices. At the same time, in order to get the best optical effect, the common limestone ore material is replaced by dolomite. AH-70 bitumen is also used in this case.

Fig. 7 shows the diagram after cutting 


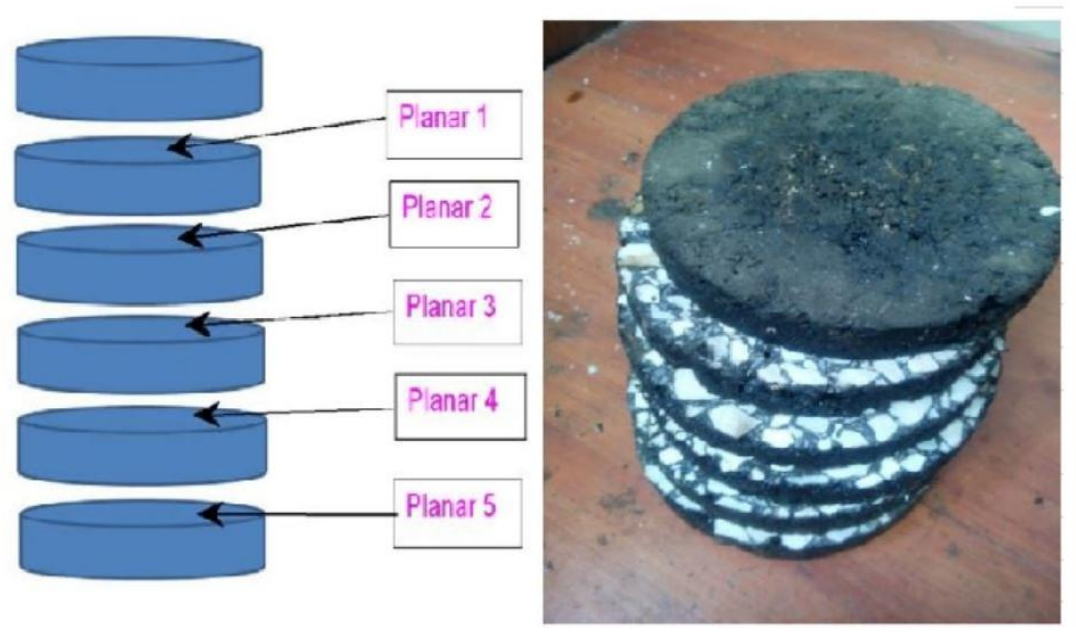

Fig. 7. Cutting diagram

Table 5 shows the gradation of mixtures of all the specimens.

Table. 5. The gradation of mixtures of all the specimens.

\begin{tabular}{|c|c|c|c|c|c|c|c|c|c|c|c|c|c|}
\hline $\begin{array}{l}\text { Sieve } \\
\text { size }(\mathrm{mm} \\
)\end{array}$ & 19 & 16 & $\begin{array}{l}13 . \\
2\end{array}$ & 9.5 & $\begin{array}{l}4.7 \\
5\end{array}$ & $\begin{array}{l}2.3 \\
6\end{array}$ & $\begin{array}{l}1.1 \\
8\end{array}$ & $\begin{array}{l}0 . \\
6\end{array}$ & $\begin{array}{l}0 . \\
3\end{array}$ & $\begin{array}{l}0.1 \\
5\end{array}$ & $\begin{array}{l}0.07 \\
5\end{array}$ & $\begin{array}{l}\text { Miner } \\
\text { al } \\
\text { powde } \\
\mathrm{r}\end{array}$ & $\begin{array}{l}\text { tar-rubbl } \\
\text { e }\end{array}$ \\
\hline $\begin{array}{l}\text { Gradatio } \\
\mathrm{n}(\%)\end{array}$ & $\begin{array}{l}1 . \\
9\end{array}$ & $\begin{array}{l}14 . \\
3\end{array}$ & $\begin{array}{l}12 . \\
9\end{array}$ & $\begin{array}{l}16 . \\
8\end{array}$ & $\begin{array}{l}18 . \\
7\end{array}$ & 9 & 7.5 & $\begin{array}{l}5 . \\
9\end{array}$ & $\begin{array}{l}3 . \\
4\end{array}$ & 2 & 2.7 & 4.9 & 4.2 \\
\hline
\end{tabular}

Fig. 8 displays the instrument for the process to obtain cross-sectional images.

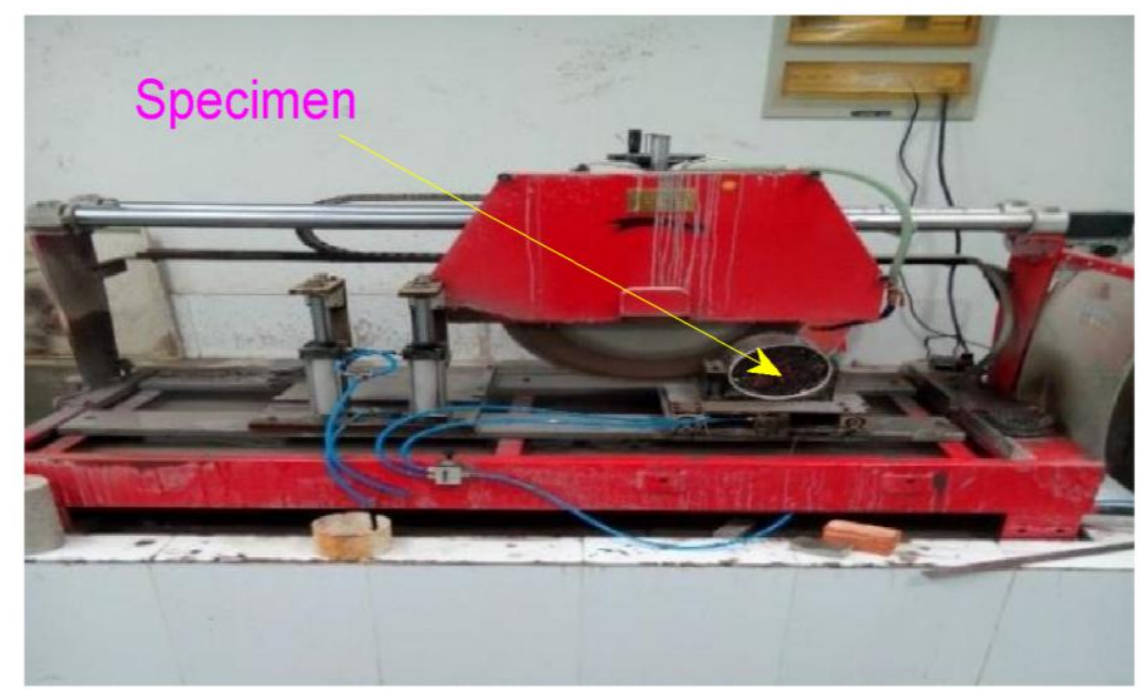

Fig. 8. Instrument for the process to obtain the specimens in laboratory 
First of all, these images are pre-processed, with gray processing and tailoring. Then the median filter algorithm is used to process the droplet images. The dolomite which is employed as the coarse aggregate provides good conditions for image segmentation. The image resolution is adjusted to $564 \times 564$.

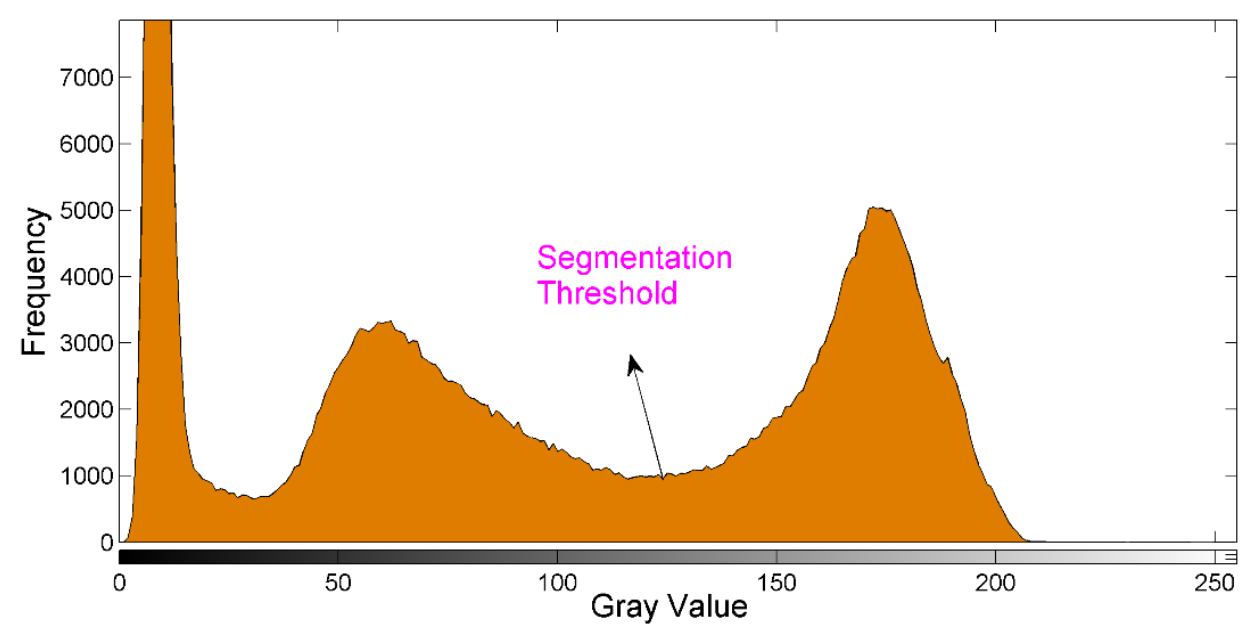

Fig. 9. Gray histogram of cross section image

The OTSU threshold method (maximum inter-class variance method) is adopted, which is extensively applied in image segmentation for being simple and intuitive, to confirm the threshold of binary image.

The OTSU method uses the concept of clustering, to classify the grey level of the image into two categories so that the inter-class grey level difference is maximized and the difference of inner-class grey level is minimized. An optimal grey level segmentation is found by computing the variance.

The binary images separate the aggregates with open operation. Then these are processed by filling up the holes. Next the images are processed by morphological operations to filter different particle sizes of coarse aggregates [16]. Finally, the diameter of the circles, which have the same area of the 2D coarse aggregates, are obtained.

Fig. 10 is the image of processing of coarse aggregates. 

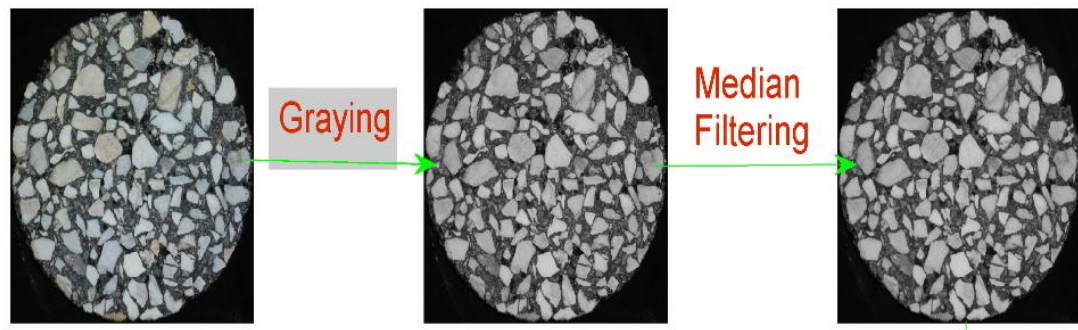

Binarization

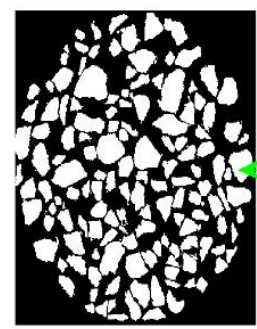

Remove

Fine

Aggragate

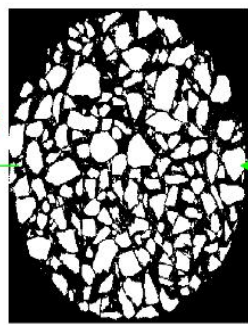

Hole

Filling

Fig. 10. Image processing for coarse aggregate

\section{Results and discussion}

The data obtained from the particles, whose diameters are below $4.75 \mathrm{~mm}$ are neglected, since these kinds of particles cannot be considered as coarse aggregates. Fig. 11 shows the frequency histograms based on diameters of different- sized particles, whose data is obtained from the crosssectional images.

After 30 times compaction, 2D aggregates, whose diameters are above $19 \mathrm{~mm}$, are not found. 

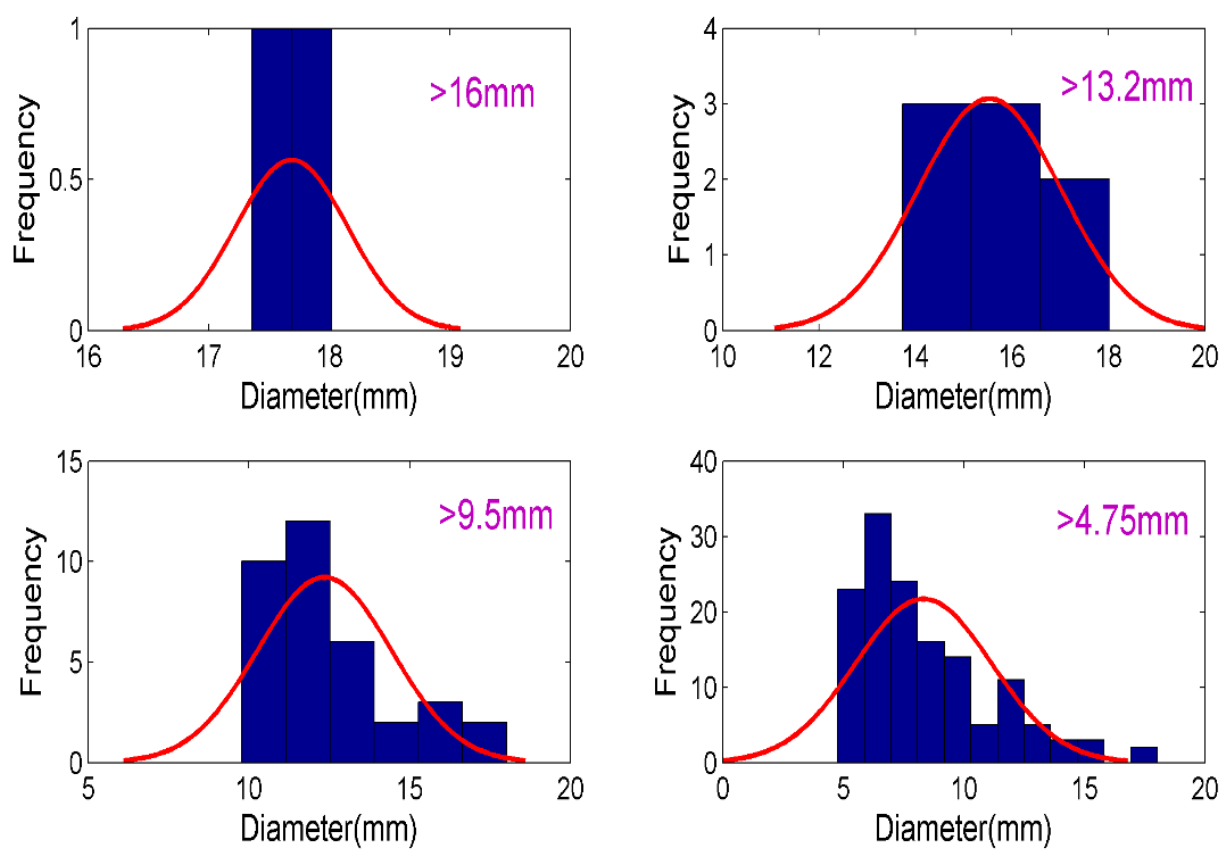

Fig. 11. 2D- histograms of coarse aggregates obtained using sieves of different sizes

\subsection{Average diameter analysis}

First of all, the changes in the sizes of the 2D coarse aggregate particles under different compaction efforts are tested. The diameters of 2D coarse aggregates are the average of diameters, from five planar images for each sample.

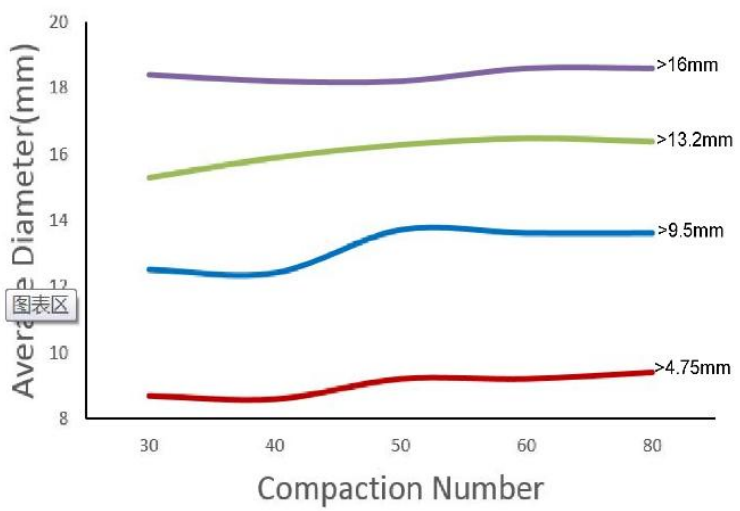

Fig. 12. The average diameters under different compaction efforts

Fig. 12 shows the changes in the diameters under different compaction efforts. For a certain grade of the coarse aggregates, the diameter increases with the growth of the number of compaction. Hence, coarse aggregates rotate slowly. The angle between long axis and the horizontal line 
decreases with an increase of the compaction number.

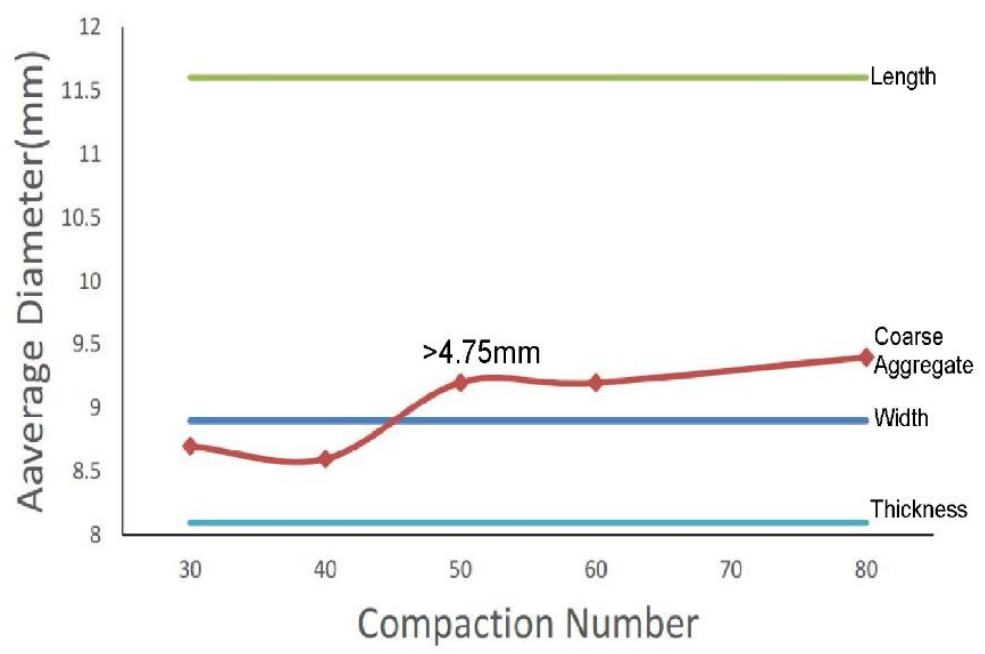

Fig. 13. The average diameters of $2 \mathrm{D}$ coarse aggregates $(>4.75 \mathrm{~mm})$ under different compaction effort

Fig. 13 shows that the rotations of the coarse aggregates are mainly between 40 times and 50 times. At this stage the average diameter exceeds the average diameter of coarse aggregates. Rotation of the coarse aggregates is not continuous during the process of formation of asphalt mixture.

Generally, the asphalt mixture forms after 80 times compaction, but the average diameter from the images of the 2D coarse aggregates cannot reach the one obtained from the model based on the length. This is manifested by the fact that the angle between long axis and the horizontal line is difficult to zero. Obviously, there is very little space for the coarse aggregates to rotate.

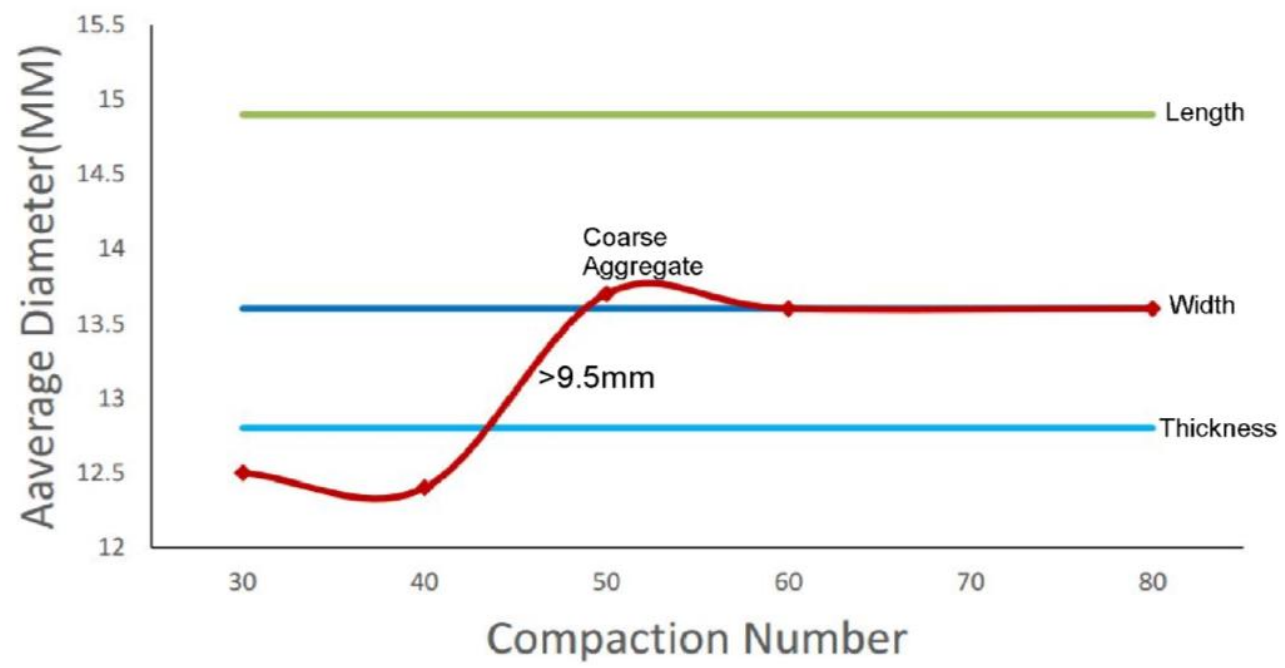




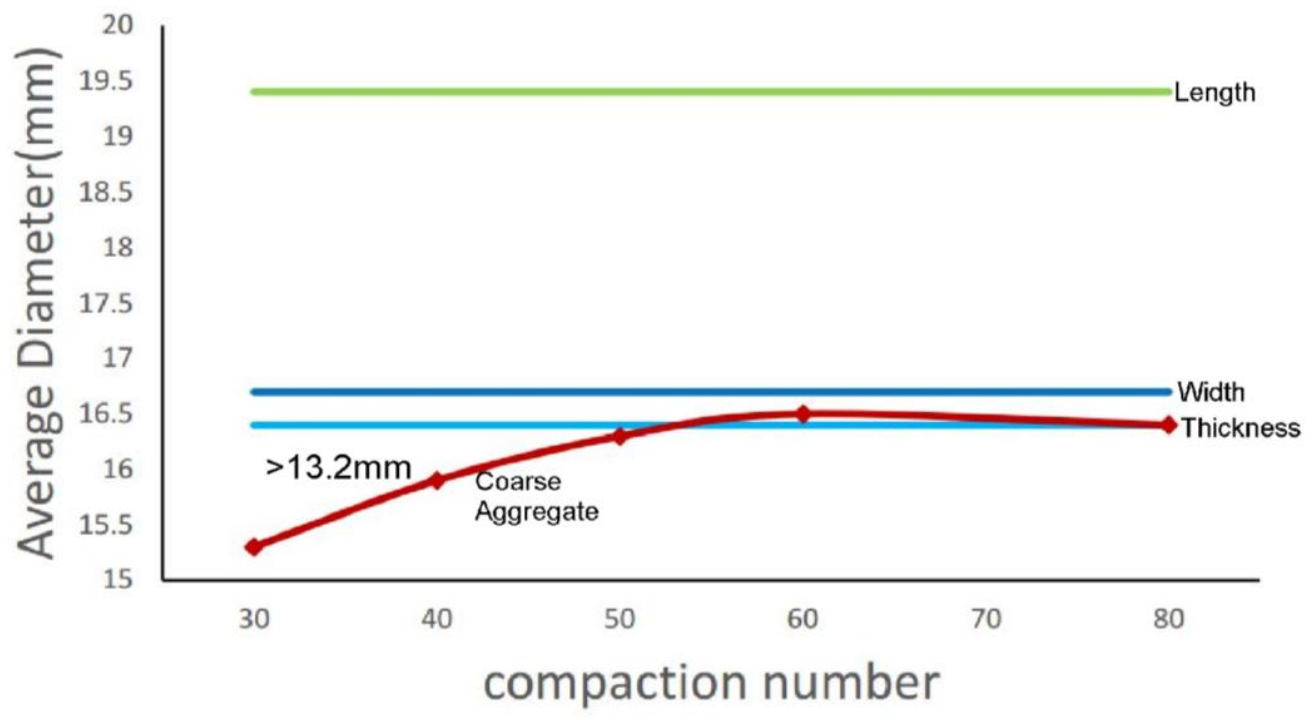

Fig. 14. The average diameter of $2 \mathrm{D}$ coarse aggregate $(>9.5 \mathrm{~mm}$ and $>13.2 \mathrm{~mm})$ under different compaction number

For larger 2D coarse aggregates $(>9.5 \mathrm{~mm}$ and $>13.2 \mathrm{~mm})$, their average diameters also increase with an increase in the compaction number. But compared to the coarse aggregates which are larger than $4.75 \mathrm{~mm}$, they are difficult to reach the average diameter from width. This can be seen in Fig. 14. This result indicates that the space for rotation of larger coarse aggregates was narrower than that of smaller aggregates. To ensure this, normally the average diameter of larger 2D coarse aggregate is kept below than that obtained from the model, based on thickness, after less compaction times. This is because the horizontal of test die is limited.

\subsection{Standard deviation analysis}

In order to supplement the analysis results obtained above, standard deviations were also studied. Fig. 15 shows that for a compaction from 30 times to 80 times, an increase in standard deviations of diameter is evident. Then, the changes in the curves of the standard deviation, with different compaction times, are obtained by polynomial fitting. The fitting formulae are given below.

$\mathrm{D}=-0.0286 n^{2}+0.3914 n+2.64$

$R^{2}=0.9909$ 


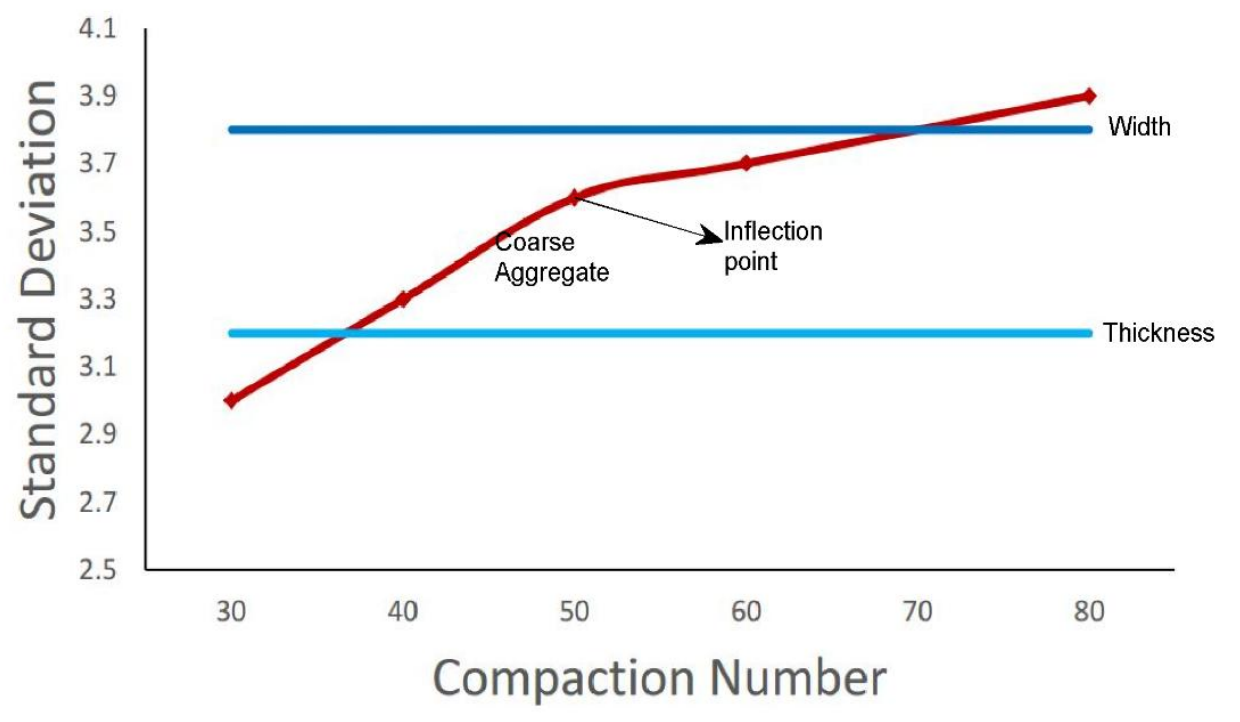

Fig. 15. Standard deviation for diameter, thickness, width of 2D coarse aggregate under different compaction efforts

Fig.15 shows that with increasing standard deviation, there is a better packing effect of coarse aggregate. When the bituminous mixture is formed after compaction of 80 times, the standard deviation was larger than that obtained from the modeling based on width. As the compaction time increases from 50 to 80, the standard deviation increases slowly. This trend of complete change implies that there may be considerable number of breakages of coarse aggregates occurring between compaction of 40 to 60 times.

\section{Conclusions}

2D mathematical model for the diameters of coarse aggregates was constructed to investigate the formation characteristics of asphalt mixture, statistically, during the gyratory compaction process. The average diameters obtained from AC20 model were compared with those obtained directly from the AC20 cross-sectional images in the laboratory. The standard deviations were also studied in this paper. The following conclusions could be drawn.

1. Using the existing statistical parameters of coarse aggregates, a mathematical model was created to study the formation process of asphalt mixture. As long as gradation of the asphalt mixture is known, the 2D distribution characteristics of coarse aggregate diameters can be obtained theoretically.

2. With an increase in the compaction times, the average diameter of 2D coarse aggregate also increases. The diameters of coarse aggregates increase rapidly when the compaction increases from 40 to 50 times. For most of the coarse aggregates, the angle between the length of the coarse aggregate and the horizontal plane is hardly zero. The space for the coarse aggregates to rotate is not large enough.

3. The packing effect of coarse aggregates gets better when compaction times increase. 
Breakage of coarse aggregates possibly occurs when compaction is 40 60times.

\section{Acknowledgement}

Authors would like to acknowledge the financial support provided by National Science Foundation through the project 51378123 and Natural Science Foundation of Jiangsu Province (BK20140109). The funding supported the specimens generated and image processing. In addition, the authors also acknowledge Dr Dong Zhang from Nanjing University of Technology for his help in information analysis. Thanks -The Sobute New Materials Co. Ltd., for the efforts in cutting the specimens.

\section{References}

1. Masad E, Muhunthan B, Shashidhar N.et al.Quantifying laboratory compaction effects on the internal structure of asphalt concrete [J]. Transporsportation Research Record: Journal of the transportation Research Board, 1999, 1691:179-185.

2. Al-Rousan T, Masad E, Tutumluer E, Pan T. Evaluation of image analysis techniques for quantifying aggregate shape characteristics. Construction and Building Materials.2007; 21(5):978-90.

3. Liu Y, You Z P. Visualization and simulation of asphalt concrete with randomly generated three-dimensional models[J].Journal of computing in civil Engineering,2009,23(6):340-347.

4. Fernlund JMR. Image analysis method for determining 3-D shape of coarse aggregate [J]. Cement and Concrete Research 2005; 35(8):1629-1637.

5. Wang LB, Wang XR, Mohammad L, Abadie C. Unified method to quantify aggregate shape, angularity and texture using Fourier analysis. Journal of Materials in Civil Engineering 2005; 17(5):498-504.

6. Dong Zhang, Xiaoming Huang, Yongli Zhao. Algorithms for Generating Three-

Dimensional Aggregates and Asphalt Mixture Samples by the Discrete Element Method [J]. Journal of Computing in civil Engineering,2013; 27 (2): 111-117,

7. Sefidmazgi NR,Tashman L,Bahia H. Internal structure characterization of asphalt mixtures for rutting performance using imaging analysis. Road Materials and Pavement Design. Des 13(sup1):21-37.

8. Abdul Hassan N, Airey GD, Hainin MR. Characterisation of micro-structural damage in asphalt mixtures using image analysis. Construction and Building Materials.2014; 54:27-38.

9. Al-Rousan T, Masad E, Tutumluer E, Pan T. Evaluation of image analysis techniques for quantifying aggregate shape characteristics. Construction Build Materials 2007; 21:978-90.

10. Leonardo Bruno, Giuseppe Parla, Clara Celauro. Image analysis for detecting aggregate gradation in asphalt mixture from planar images. Construction and Building Materials.2012; 28:21-30.

11. Ki Hoon Moon. Microstructural analysis of asphalt mixtures using digital image processing techniques. Canadian Journal of Civil Engineering (CJCE) 2014; 41(1):74-86. 
12. Zhang Deyu, Bai Tao,Huang Xiaoming .Analysis of space movement of coarse aggregate during permanent deformation of asphalt mixture[J] (In Chinese). Journal of building materials 2015, 18(3):438-444.

13. Yongli Zhao. The study on mechanism asphalt mixture composition [D] (In Chinese), 2005. 45-66.

14. Dong zhang, xiaoming Huang, Yongli Zhao. Investigation of the shape, size, angularity and surface Texture properties of Coarse Aggregates [J].Construction and Building Materials.2012, 34:330-336

15. Muraya M. Homogeneous test specimens from gyratory compaction. International Journal of Pavement Engineering. 2007; 8(3):225-35.

16. Ki Hoon Moon, Michael P Wistuba. Analyzing aggregate size distribution of asphalt mixtures using simple 2D digital image processing techniques. Arabian Journal for Science and Engineering.2015; 40(2):1309-26. 